\title{
A cross-sectional study on knowledge and implementation of the nursing process among nurses at Muhimbili National Hospital-Tanzania
}

\author{
Happiness Obonyo ${ }^{1}$, Edith A.M Tarimo²*1, Fatina Ramadhan³ ${ }^{3}$ and Secilia Ng'weshemi Kapalata ${ }^{4}$ \\ ${ }^{1}$ The University of Dodoma Hospital, P.O Box 259, Dodoma, Tanzania \\ ${ }^{2}$ Department of Nursing Management, Muhimbili University of Health and Allied Sciences, P.O Box 65001, Dar \\ es salaam, Tanzania \\ ${ }^{3}$ Department of Clinical Nursing, Muhimbili University of Health and Allied Sciences, P.O Box 65001, Dar es \\ salaam, Tanzania \\ ${ }^{4}$ Department of Public Health, The University of Dodoma, College of Health Sciences (UDOM), P.O Box 854, \\ Dodoma, Tanzania.
}

\begin{abstract}
Background: The nursing process involves a series of actions that begins with assessing the patient, identifying problems, setting goals with expected outcomes, implementing care to achieve those goals and finally evaluating the effectiveness of the care given. Utilization of the nursing process to guide nursing care enhances the quality of patient care and outcomes for both the patient and family members. The purpose of this study was to assess the knowledge and implementation of the nursing process among nurses working at Muhimbili National Hospital, Dar es Salaam, Tanzania.

Methods: We conducted a descriptive cross-sectional study design. A convenient sample of 102 registered nurses $(\mathrm{RN})$ completed a self-administered questionnaire in April 2016. Descriptive statistics and nonparametric tests were used to assess the significance levels of associated variables.

Results: Of 102 respondents, only 16 (15.7\%) had high knowledge of the nursing process. Similarly, a few (11, $10.8 \%$ ) respondents had a high level of practice. The majority of RN (94, 92.2\%) were aware of the role of the nurses in providing care to admitted patients. However, only a few $(32,31.4 \%)$ were aware of the purpose of the nursing process. Respondents were more likely to have high knowledge in the nursing process if they had a diploma in nursing education $(95 \% \mathrm{Cl} 0.000-0.029, p<0.01)$. The small number of nurses in the ward and inadequate motivational strategies were reported to deprive the implementation of the nursing process.

Conclusion: Overall, low knowledge of the nursing process, understaffing and workload have contributed to the ineffective implementation of the nursing process. On-the-job refresher courses are a short-term strategy that may improve the nurses' knowledge and motivation to implement the nursing process. This study underscores the need for policymakers to advocate for the employment of a sufficient number of nurses to enable implementation of the nursing process to all admitted patients.
\end{abstract}

Keywords: Knowledge; Implementation; Nursing Process; Tanzania

\section{Introduction}

The advancement of the nursing profession necessitates the application of a logical and rational method of problem-solving in making decisions about patient care. Nurses acquire and use information from nursing practice, nursing theories, and other sciences to apply knowledge to individual situations (Aliyedun \& Chukwu, 2014). According to the World Health Organization (WHO, 2005), the nursing process is an organized sequence of problem-solving steps used to identify and manage the health problems of patients. It is a systematic method which utilizes scientific reasoning, problem-solving, and critical thinking to direct nurses to care for patients effectively. The nursing process also sets a global standard upon which nursing care can be audited and reduces patients anxiety (Carole, et al., 2015; Harcourt, et. al., 2013).

\footnotetext{
1 *Corresponding author: edithtarimo@gmail.com
} 
Volume 21, Number 2, August 2019

Furthermore, a nurse is required to think critically and to be creative when solving patients' problems (Haapoja, 2014; Harcourt, et al., 2013; Kozier, et. al., 2004). Thus, the growth of nursing as a profession has necessitated the application of a logical and rational method of problem-solving in making decisions about patient care, instead of relying on unsystematic and intuitive processes. A previous study conducted in Kenya shows that when better nursing care is implemented, the number of hospital stays are reduced due to quality of the nursing care in hospitals (Carole, et al., 2015). A study on application of the nursing process in Mekelle zone hospitals in northern Ethiopia revealed that $100 \%$ of nurses did not use the nursing process during the provision of care to the patients during all period of their study (Hagos, et. al., 2014).

Further, the study posited that $75 \%$ of nurses failed to use the nursing process due to the nurse to patient ratio (overcrowding) (Hagos, et. al., 2014). Similar challenges were found in Abuja Teaching Hospital in Nigeria where a shortage of workforce was the major challenge, followed by a poor attitude of nurses towards documentation and time constraint (Adeyemo \& Olaogun, 2005; Akbari \& Shamsi, 2011). Another study at Ibadan hospitals revealed that utilization of the nursing process in the three hospitals was associated with problems in history taking, formulation of nursing diagnosis, nursing orders, and evaluation. Most nurses did not agree with the use of authorized abbreviations and symbols. However, the study concluded that most nurses knew and understood the importance of documentation and that, nurses need continuing professional education practice and supervision (Hagos, et al., 2014; Ofi \& Sowumi, 2012).

The use of nursing process enhances quality patient care and outcome for both the patient and family members. It is an organizational framework for the practice of nursing which encompasses all steps taken by the nurse in caring for a patient: assessment, nursing diagnoses, planning (with goals and outcome criteria), implementation of the plan (with patient teaching), and evaluation (Mahmoud \& Bayoumy, 2014; Shewangizaw \& Mersha, 2015). Provision of quality care is determined by the functioning human and non-human resources available to provide care and treatment (Ministry of Health Community Development Gender Elderly and Children, 2010). At the same time, there is a lack of documentation of the nursing process, which leads to inadequate nursing care (Mamseri, 2012). In responding to the current nursing situation, Tanzania Nurses and Midwifery Council had established a strategy of ensuring that the nursing process is practiced in all health facilities. This strategy led to the establishment of the Tanzanian Nursing Practice Model formulated by the Nursing Services Unit of the Ministry of Health (Ministry of Health and Social Welfare, 2002). Therefore, the primary aim of using nursing process is to understand the health status and the problems of clients which may be actual or potential, and to address those problems logically (Adeyemo \& Olaogun, 2005).

Improving the quality of nursing care is an important approach to improve patient outcomes. Since the establishment of the Nursing Practice Model formulated by the Nursing Services Unit at the Ministry of Health and Social Welfare in Tanzania in 2002, little has been documented on its current status. The present study was justified as a follow up of status of implementation of the nursing process. Hence, the purpose of this study was to assess the knowledge and implementation of the nursing process among nurses working at Paediatric New Complex (PNC) Muhimbili National Hospital, Dar es Salaam, Tanzania.

\section{Methods}

\section{Setting and population}

This descriptive cross-sectional study was carried out in Pediatric New Complex Unit (PNCU) at Muhimbili National Hospital (MNH). MNH is the national hospital as well as teaching hospital located at Ilala District in Dar es Salaam Region with 1,500-bed capacity. This area was chosen because most patients with complicated conditions, such as children with pneumonia are referred to $\mathrm{MNH}$ for health services, including nursing care. The PNCU has highly qualified 
personnel as well as modern equipment. PNCU consists of the following wards: Makuti A, Makuti B, Ward A, Ward B, Oncology, Kangaroo, burns and pediatric surgery.

\section{Sample and sampling}

All registered nurses who were licensed by Tanzania Nurses and Midwifery Council and who were available at the MNH workplace were conveniently recruited in the study. The registered and licensed to practice nurses comprised of three categories: two years certificate trained nurses (enrolled nurses), three years diploma trained nurses (assistant nursing officers), and four years degree trained nurses (nursing officers). Also, all nurses trained at a postgraduate level, such as Master's and Ph.D. are currently categorized as the nursing officers. Thus, a total of 102 registered and licensed to practice nurses were conveniently sampled.

\section{Data collection}

Data were collected using a self-administered structured questionnaire in April 2016. The questionnaire consisted of three sections: Section A: Socio-demographic information, and knowledge; Section B: Practice assessment; and Section C: Factors influencing the implementation of the nursing process. In order to ensure tool validity, three senior nursing professionals reviewed the questionnaire. We conducted a pre-test of the tool to establish validity and reliability. In this case, the questionnaire was pre-tested by five nursing officers who were working in the office of the Director of Nursing Services $\mathrm{MNH}$; three enrolled nurses from Muhimbili Orthopedic Institute (MOI) and two nursing students to evaluate if the nurses would understand the questions. Based on the pre-test, all items were understood. To ensure the reliability of the instrument, the first author calculated Cronbach's Coefficient during the pre-test using Statistical Package for the Social Sciences (SPSS) version 20 software. The results showed that all Cronbach Coefficient was above 0.7, which is the minimum acceptable value. The overall Cronbach's alpha was 0.782 .

\section{Data analysis}

Data were entered, cleaned, coded, and analyzed using SPSS version 20. Chi-square test was used to assess the significance levels of associated variables to the Nursing Process. Bivariate analysis was done to evaluate whether knowledge score was associated with socio-demographic characteristics.

Level of knowledge was measured using a grading scale adopted from the Tanzania Ministry of Health Training Unit (Ministry of Health and Social Welfare, 2002). We modified the grading scale of competence into three categories, among seven questions; each question was assigned 14 marks. Therefore, those who answered five to seven questions correctly scored $70 \%$ and above and were regarded as having high knowledge. A score of $50 \%$ to $69 \%$ by answering three to four questions correct was regarded as having moderate knowledge while those who scored $<50 \%$ by correctly answering two or fewer questions were regarded as having poor knowledge. Variables with $p$-value of $<0.05$ at $95 \%$ confidence interval $(\mathrm{Cl})$ were declared significant.

The use of the convenient sampling method limits the generalization of these results. It was not possible to sample the potential respondents randomly because of several reasons, being a working shift and the limited number of nurses. Depending on staff shift such as morning, evening, night, and off duty, some of the respondents were not on duty during the period of data collection. The author minimized this limitation by distributing questionnaires in all shifts and followed off-duty nurses to respond when on duty.

\section{Results}

\section{Socio-demographic characteristics}


Volume 21, Number 2, August 2019

Female respondents formed the most substantial study group $(94,92.2 \%)$ with a mean age $( \pm S D)$ of 41 years $( \pm 11)$. Majority of the respondents $(32,31.4 \%)$ belonged to the age group of $24-33$ years old. About half $(57,55.9 \%)$ of the respondents had a diploma in general nursing education and were employed as assistant nursing officers. The results further showed that a majority of respondents $(64,62.7 \%)$ had worked between one and six years (Table 1$)$.

Table 1. Socio-demographic characteristics of respondents $(\mathrm{N}=102)$

\begin{tabular}{lcc}
\hline Variable & Frequency & Percent (\%) \\
\hline Gender & 8 & 7.8 \\
Male & 94 & 92.2 \\
Female & & \\
Age of respondents & 32 & 31.4 \\
$24-33$ & 23 & 22.5 \\
$34-43$ & 30 & 29.4 \\
$44-53$ & 17 & 16.7 \\
54 and above & & \\
Employment position & 35 & 34.3 \\
Enrolled nurse & 57 & 55.9 \\
Assistant nursing officer & 10 & 9.8 \\
Nursing officer & & \\
Education level & 35 & 34.3 \\
Certificate & 57 & 55.9 \\
Diploma & 9 & 8.8 \\
Bachelor degree & 1 & 1.0 \\
Master's degree and above & & \\
Working experience & 64 & 62.7 \\
1-6 years & 22 & 21.6 \\
7-14 years & 16 & 15.7 \\
\hline
\end{tabular}

\section{Knowledge of the implementation of the nursing process}

Only $16(15.7 \%)$ respondents had high knowledge while half had moderate and 35 (34.3\%) had poor knowledge about the implementation of the nursing process.

\section{Respondents' awareness of the implementation of the nursing process}

Although the majority of respondents (92.2\%) were aware of their role in providing care to admitted patients, only a few (31.4\%) were aware of the purpose of the nursing process (Table 2 ).

Table 2. A summarized description of respondents' knowledge of various aspects of the nursing process

\begin{tabular}{llcc}
\hline S/N & Description of questions & Correct & Percent (\%) \\
\hline 1 & Awareness of steps of the nursing process & 79 & 77.5 \\
2 & Awareness of purpose of the nursing process & 32 & 31.4 \\
3 & Ever been involved in the planning of patient care & 61 & 59.8 \\
4 & $\begin{array}{l}\text { The perception that implementation of the nursing } \\
\text { process depends on doctor assessment }\end{array}$ & 73 & 71.6 \\
5 & $\begin{array}{l}\text { Awareness that it is the role of nurses to implement the } \\
\text { nursing process }\end{array}$ & 94 & 92.2 \\
6 & $\begin{array}{l}\text { Aware of the most appropriate definition of a nursing care } \\
\text { plan }\end{array}$ & 88 & 86.3 \\
7 & $\begin{array}{l}\text { The perception that initiation of nursing care plan entirely } \\
\text { depends on the seriousness of a patient }\end{array}$ & 84 & 82.4
\end{tabular}




\section{Knowledge level and socio-demographic characteristic}

Bivariate analysis showed that nurses were more likely to have good knowledge of nursing process if they had a diploma level of nursing education ( $95 \% \mathrm{Cl} 0.000-0.029, \mathrm{P}<0.01$ ) (Table 3 ).

Table 3. Association between knowledge level and socio-demographic characteristics on the implementation of the nursing process

\begin{tabular}{|c|c|c|c|c|}
\hline $\begin{array}{l}\text { Socio-demographic } \\
\text { Characteristics }\end{array}$ & $\begin{array}{l}\text { Higher Knowledge } \\
\text { n (\%) }\end{array}$ & $\begin{array}{l}\text { Moderate } \\
\text { Knowledge } \\
\text { n (\%) }\end{array}$ & $\begin{array}{l}\text { Poor } \\
\text { Knowledge } \\
\text { n (\%) }\end{array}$ & p-value $(95 \% \mathrm{Cl})$ \\
\hline \multicolumn{5}{|l|}{ Age of Respondents } \\
\hline $24-33$ & $4(12.5)$ & $19(59 \cdot 4)$ & $9(28.1)$ & \multirow{4}{*}{$0.839(0.433-0.626)$} \\
\hline $34-43$ & $3(13.0)$ & $12(52.2)$ & $8(34.8)$ & \\
\hline $44-53$ & $5(16.7)$ & $13(43 \cdot 3)$ & $12(40.0)$ & \\
\hline 54 and above & $4(23 \cdot 50)$ & $7(41.2)$ & $6(35 \cdot 3)$ & \\
\hline \multicolumn{5}{|l|}{ Sex } \\
\hline Male & $0(0.0)$ & $6(75.0)$ & $2(25.0)$ & \\
\hline Female & $16(15 \cdot 7)$ & $45(47.9)$. & $33(34 \cdot 3)$ & $0.624(0.413-0.607)$ \\
\hline \multicolumn{5}{|l|}{ Education level } \\
\hline Certificate & $2(5.7)$ & $14(40.0)$ & $19(54 \cdot 3)$ & \multirow[b]{2}{*}{$0.009 * *(0.000-0.029)$} \\
\hline $\begin{array}{l}\text { Diploma } \\
\text { Bachelor degree and } \\
\text { above }\end{array}$ & $13(22.8)$ & $29(50.9)$ & $\begin{array}{l}15(26.3) \\
1(10.0)\end{array}$ & \\
\hline \multicolumn{5}{|l|}{ Working experience } \\
\hline $1-6$ years & $9(14.1)$ & $32(50.0)$ & $23(35.9)$ & \multirow{3}{*}{$0.420(0.433-0.626)$} \\
\hline 7-14years & $6(27 \cdot 3)$ & $9(40.9)$ & $7(31.8)$ & \\
\hline 15 years and above & $1(6.3)$ & $10(62.5)$ & $5(31.3)$ & \\
\hline
\end{tabular}

** Significance denoted by $\mathrm{P}<0.01$

\section{Respondents' practice about the implementation of the nursing process}

Regarding respondents' current practice, only a few (11,10.8\%) reported a high level of practice while about half $(51.0 \%)$ had good and 39 (38.2\%) had poor practices on implementing the nursing process.

\section{Respondents' responses about specific practices questions}

All respondents (100\%) reported that they always take and record vital signs when the child is admitted. However, less than half (46.1\%) initiated nursing care plan (Table 4).

Table 4. Respondents' responses about specific practices of implementation of the nursing process $(\mathrm{N}=102)$ 


\begin{tabular}{llcc} 
SN & Description of questions & Yes & Percentages \\
\hline 1 & Do you take and record vital signs when a child is admitted? & 102 & 100 \\
2 & Do you conclude the assessment data that describe the & 95 & 93.1 \\
& patient's needs? & 47 & 46.1 \\
3 & Do you initiate nursing care plan for every child? & 78 & 76.5 \\
4 & Do you intervene when the death of children increases? & 92 & 90.2 \\
5 & Do you evaluate nursing activities? & \\
\hline
\end{tabular}

\section{Practice levels on the implementation of the nursing process and socio-demographic characteristics}

The majority of the respondents (66.7\%) aged 44-53 years reported having a moderate level of practice and those aged 54 years and above (23.5\%) reported having a good level of practice. Regarding education status, degree holders and above were reported to have a good level of practice (20.0\%) compared with the diploma and certificate holders. Overall, there was no statistical significance between the implementation of the nursing process and socialdemographic characteristics.

\section{Perception of factors influencing the implementation of the nursing process}

The nurses' perceptions of the factors influencing the implementation of the nursing process were assessed by, a "yes/no" responses. The majority ( $87 \%$ ) of the respondents perceived that patients' satisfaction highly influenced the implementation of the nursing process. Also, they perceived that the nurse-patient ratio and the availability of resources such as stationery influenced the implementation of the nursing process. Furthermore, the respondents perceived that the lack of knowledge or skills, and motivation to work among the nurses hampered the implementation of the nursing process.

Overall, these results indicate that the majority of respondents were aware of the nursing process, but a few implemented it due to inadequate staffing and limited resources.

\section{Discussion}

Overall, few respondents had high knowledge of the nursing process. Similarly, few respondents had a high level of practice. The majority were aware of the role of the nurses in providing care to admitted patients. However, only a few were aware of the purpose of the nursing process. Respondents were more likely to have high knowledge in nursing care process if they had been educated at the diploma level. The nurse to patient ratio and availability of resources were reported to discourage the implementation of the nursing process.

The respondents' overall knowledge level on the implementation of the nursing process was moderate. This average knowledge scores on the implementation of the nursing process were contrary to the initial assumption that nurses have high knowledge of the nursing process because the nursing process was part of the basic professional educational program. On the other hand, the bivariate analysis shows that nurses were more likely to have high knowledge of nursing process if they were employed as diploma graduates. The results differ from the study done in Oyo State in south-western Nigeria that established that knowledge on the nursing process amongst Bachelor degree nurses was higher than amongst diploma holders or assistant nursing officers (Adeyemo \& Olaogun, 2005). This high knowledge score implies that education level contributes to the understanding of the nursing process.

Implementation of the nursing process was found to be low in this study. This low score could be due to inadequate staffing, and availability of resources, such as stationery. This result is consistent with another study conducted in Ethiopia where almost $100 \%$ of nurses did not use nursing process during provision of care to the patients due to unacceptable nurse to patient ratio (overcrowding) (Hagos, et al., 2014). Although there were some high scores of individual 
Volume 21, Number 2, August 2019

skills, there was no evidence on the association between practice and socio-demographic characteristics. The high implementation of the nursing process reported by degree graduate nurses corresponded with their level of training. Also, the fact that the implementation of the nursing process was high among respondents aged 54 years and above implies that years of experience contributes to practicing of the nursing process. Similarly, the study in Abuja Teaching Hospital, Nigeria regarding the evaluation of challenges affecting utilization of nursing process found that years of practice above 15 years was statistically significant with the utilization of nursing process (Aliyedun \& Chukwu, 2014) Overall, this trend of years of experience implies that prolonged practice contributes to proper use of the nursing process.

In routine nursing activities, every patient is supposed to be cared for by a nurse using the nursing process. Patients' satisfaction could be by the fact that when the patients feel happy with the nursing care, perhaps there will be better recovery or short hospital stays and thus the implementation of nursing care. In this study, it was observed that there is a need for health institutions or organization to improve the use of the nursing process. This strategy is in line with a previous study (Siemuri, et. al., 2014), which found that the predominant barriers to the nursing process were related to the health organization. Thus, the implementation of the nursing process in this study was affected by individual nurses and institutional factors. The proper implementation of the nursing process will lead to good nursing care as suggested by the Ontario College of Nurses (College of Nurses of Ontario, 2014).

On the other hand, when these factors negatively affect the implementation of the nursing process, there will be poor nursing care (low implementation of the nursing process). A previous study in Ethiopia showed a significant association between stressful workplace atmospheres, such as patient workload and the implementation of the nursing process (Baraki, et al., 2017). The present study recommends that the number of staff should be increased to decrease workload. Also, basic supplies plus a work-related motivation to nurses should be improved in the hospital setting for the best implementation of the nursing process.

In conclusion, this study adds knowledge in the area of nursing process and its implementation in a low-income setting. Overall, low knowledge of nursing process might have led to the ineffective implementation of the nursing process. Besides, understaffing and workload might have contributed to the poor implementation of the nursing process. On-the-job refresher courses stand as a short-term strategy that may improve nurses' knowledge as well as motivation to implement the nursing process. Also, there is a need to rigorously enforce the use of the nursing process in the educational setting for the nursing programs. Indeed, for the best patient outcome, the reported challenges should not be underrated. In practice, nurses should put more effort into updating their knowledge as well as implementing the nursing process using available resources, such as information technology. Hospital management should be enlightened about the benefits of the nursing process in terms of patients' outcome. This recognition will enhance the regular supply of the needed resources for implementing the nursing process.

Moreover, professional bodies of nursing should enforce the use of the nursing process in the care of patients, establish regulatory committees to review compliance in the utilization of the nursing process, and sanction defaulting institutions. Similarly, refresher courses, educational materials, such as current journals of nursing, audiovisuals on nursing care, and a functional quality assurance committee should be made available in each ward. Further studies should be carried out with a large random sample to ascertain the practicability of all components of the nursing process and generalization of the results. This study underscores the need for policymakers to advocate for the employment of a sufficient number of nurses to enable implementation of the nursing process to all admitted patients. Also, knowledge and skills regarding the nursing process should be enforced in the nursing curriculum across all levels of training. 
Volume 21, Number 2, August 2019

Acknowledgments: The authors would like to acknowledge all people who contributed to this study. Similarly, we appreciate the effort of all nurses working at Paediatric New Complex at Muhimbili National Hospital, who agreed to participate in the study despite the overwhelming workload during the data collection period. Dr. Anne Outwater is highly acknowledged for editing this paper.

Ethical considerations: The ethical clearance was obtained from Muhimbili University of Health and Allied Sciences (MUHAS) Institutional Review Board (IRB) Ref.No.MU/PGS/SAEC/Vol.XIV/24th March 2016. Permission to conduct the study was obtained from Executive Director of MNH, Director of Clinical Services MNH, and head of Pediatric new complex MNH. Participants' written consent was obtained before, including them in the study.

Funding source: The study was funded by Ministry of Health Community Development Gender Elderly and Children as part of Master dissertation.

Conflict of interest statement: The authors declare no competing interests.

\section{References}

Adeyemo, F. O., \& Olaogun, A. E. (2005). Factors affecting the use of Nursing process in health institutions in Ogbomoso Town, Oyo State. IJMPS, 3(1), 92-93.

Akbari, M., \& Shamsi, A. (2011). A survey on nursing process barriers from the nurses' view of intensive care units. Iranian Journal of critical care, 4(3), 181-186.

Aliyedun, J. I., \& Chukwu, L. N. (2014). Evaluation of the challenges of nursing processes practice at the University of Abuja Teaching Hospital, Nigeria. International Journal of Medical and Public Health Science Research 2, 93-100.

Baraki, Z., Girmay, F., Kidanu, K., Gerensea, H., Gezehgne, D., \& Teklay, H. (2017). A cross-sectional study on nursing process implementation and associated factors among nurses working in selected hospitals of Central and Northwest zones, Tigray Region, Ethiopia. BMC Nurs, 16, 54.

Carole, M., Wagoro, A., \& Podo, C. (2015). Mainstreaming Kenya-Nursing Process in clinical settings: The case of Kenya. International Journal of Africa Nursing Sciences, 3, 31-39.

College of Nurses of Ontario. (2014). Entry-to-Practice Competencies for Ontario Registered Practical Nurses. Retrieved Accessed 5/12/2018, from Ontario College: http://www.cno.org/globalassets/docs/reg/41042_entrypracrpn.pdf

Haapoja, A. (2014). The Nursing Process: a tool to enhance clinical care University of Applied Sciences, Novia. Bachelor of Nursing dissertation.

Hagos, F., Alemseged, F., Balcha, F., Berhe, S., \& Aregay, A. (2014). Application of Nursing Process and Its Affecting Factors among Nurses Working in Mekelle Zone Hospitals, Northern Ethiopia. Nurs Res Pract, 2014, 675212.

Harcourt, P., Afolayan, J. A., Donald, B., Baldwin, D. M., \& Onasoga, O. (2013). Evaluation of the utilization of nursing process and patient outcome in psychiatric nursing: case study of psychiatric hospital. Journal of Pelagia Research, 4(5), 34-43.

Kozier, B., Erbs, G., Berman, A., \& Synder, S. (2004). Fundermental of Nursing: Concepts, Process and Practice (7th ed.). New Jersey: Prentice Hall Hardcover.

Mahmoud, M. H., \& Bayoumy, H. M. (2014). Barriers and facilitators for execution of nursing process from nurses' perspectives. International Journal of Advanced Research, 2(2), 300-315.

Mamseri, R. A. (2012). The nursing process as a means of improving patient care. University of South Africa, Johannesburg. Master thesis: https://core.ac.uk/download/pdf/43171467.pdf.

Ministry of Health and Social Welfare. (2002). Tanzania Nursing Practice Model. Dar es Salaam: Ministry of Health.

Ministry of Health Community Development Gender Elderly and Children. (2010). Baseline survey on quality of paediatric care in Tanzania. Dar es Salaam: MoHSW, United Republic of Tanzania.

Ofi, B., \& Sowumi, O. (2012). Nursing documentation experience of the use of the nursing process model in selected hospital in Ibadan, Oyo, Nigeria. International Journal of Nursing Practice, 18, 354-362. 
Shewangizaw, Z., \& Mersha, A. (2015). Determinants towards implementation of Nursing Process. American Journal of Nursing Sciences, 4(3), 45-49.

Siemuri, K. E., Oladayo, O. F., \& Ugochukwu, N. C. (2014). Factors influencing the utilization of the nursing process in Ogun State, Nigeria. International Journal of General Medicine and Pharmacy, 3(2), 57-64.

WHO. (2005). Child and adolescent mental health policies and plans: Mental health policy and service guidance package. Geneva. 